\title{
Polymer-Like Polyphenols of Black Tea and Their Lipase and Amylase Inhibitory Activities
}

\author{
Rie Kusano, Hisashi Andou, Miho Fujeded, Takashi Tanaka, * Yosuke Matsuo, and Isao Kouno* \\ Graduate School of Biomedical Sciences, Nagasaki University; 1-14 Bunkyo Machi, Nagasaki 852-8521, Japan. \\ Received September 25, 2007; accepted December 11, 2007; published online December 13, 2007
}

\begin{abstract}
Lipase and amylase inhibitory activities of black tea were examined. After solvent partitioning of a black tea extract with the ethyl acetate and $n$-butanol, the two soluble fractions showed comparable inhibitory activities. Activity in the ethyl acetate fraction was mainly attributable to polyphenols with low-molecular weights, such as theaflavin gallates. On the other hand, the active substance in the $\boldsymbol{n}$-butanol layer was ascertained to be a polymer-like substance. ${ }^{1} \mathrm{H}$ - and ${ }^{13} \mathrm{C}$-NMR spectra showed signals arising from the flavan A-ring and galloyl groups, although signals due to flavan B-rings were not detected, suggesting that the polymer-like substances were generated by oxidative condensation of flavan B-rings, a result which was previously deduced from our results of in vitro catechin oxidation experiments. Enzymatic oxidation of epicatechin 3-O-gallate produced a similar polymer-like substance and suggested that condensation between a B-ring and galloyl groups was involved in the polymerization reaction.
\end{abstract}

Key words black tea; lipase; amylase; polyphenol; oxidation; thearubigin

Black tea, which is one of the most widely drunk beverages in the world, is produced by fermentation of the fresh leaves of Camellia sinensis. During the fermentation process, the constituents of the leaves are enzymatically converted to numerous secondary products that contribute to the characteristic color and flavor of black tea. ${ }^{1,2)}$ The tea catechins, in particular, are major constituents of fresh tea leaves and are mainly composed of (-)-epicatechin, (-)-epigallocatechin and their galloyl esters. These constituents are oxidized during fermentation to yield a complex mixture of secondary polyphenols including theaflavins, ${ }^{3)}$ theasinensins ${ }^{4,5)}$ and oolongtheanins. ${ }^{5)}$ However, most of the secondary polyphenols in black tea have not yet been chemically characterized because of their complexity and the difficulties associated with their separation and purification. ${ }^{6)}$ Despite this lack of knowledge concerning their chemical structures, the health benefits of black tea polyphenols are well known, and include antioxidant, $^{7)}$ anticancer ${ }^{8,9)}$ and anti-inflammatory ${ }^{10,11)}$ effects. The black tea polyphenols, represented by the theaflavins and theasinensins, have larger molecular weights than those of the monomeric tea catechins; therefore, the extent of direct absorption of the polyphenols by the digestive tract is expected to be lower than for tea catechins. ${ }^{12)}$ When we consider the contribution of black tea to human health, the inhibition of digestive enzymes may have considerable importance, since polyphenols with high molecular weights have an inherent ability to interact with proteins by forming hydrophobic and hydrogen bonds, ${ }^{13,14)}$ which usually results in enzyme inhibition. ${ }^{15)}$ Amylase and lipase are digestive enzymes that hydrolyze starch and triglyceride, respectively, and inhibition of these enzymes has been linked to the decreased incidence of common diseases caused by diets rich in carbohydrates and fats. It has been reported that theaflavins exhibit inhibitory activities against these enzymes ${ }^{16-18)}$; however, the concentrations of theaflavins in black tea infusions were much lower than other water-soluble polyphenols (Fig. 1). ${ }^{6,13)}$ This paper describes the importance of the polymer-like polyphenols in black tea by showing their enzyme inhibitory activities, as well as presenting their chemical characterization and possible biogenesis.

\section{Result and Discussion}

Lipase and $\alpha$-Amylase Inhibitory Activity of Black Tea Commercial black tea was first extracted with cold water and then with aqueous acetone. The aqueous acetone extract was further fractionated by solvent partitioning to produce ether (yields of $3.2 \%$ of the black tea dry weight), EtOAc (4.7\%), $n$ - $\mathrm{BuOH}(10.6 \%)$ and aqueous $(9.0 \%)$ layers, along with an insoluble paste-like precipitate $(0.5 \%)$. The first cold water extract contained mainly sugars and other polar substances, and the ether fraction contained chlorophylls and other nonpolar compounds; these fractions showed only weak lipase inhibitory activity (data not shown). On the other hand, the EtOAc, $n-\mathrm{BuOH}$, aqueous layers and insoluble precipitate showed inhibitory activities of $47.7 \%, 46.8 \%, 28.3 \%$ and $61.1 \%$, respectively (Table 1 ).

HPLC analysis of the EtOAct layer (Fig. 2), which showed strong inhibition, revealed sharp peaks due to caffeine, monomeric catechins [(-)-epigallocatechin 3-O-gallate (1), $(-)$-epicatechin 3-O-gallate (2), and epicatechin], theaflavins (3-5), and theasinensin A (6) (Fig. 3). The activities of

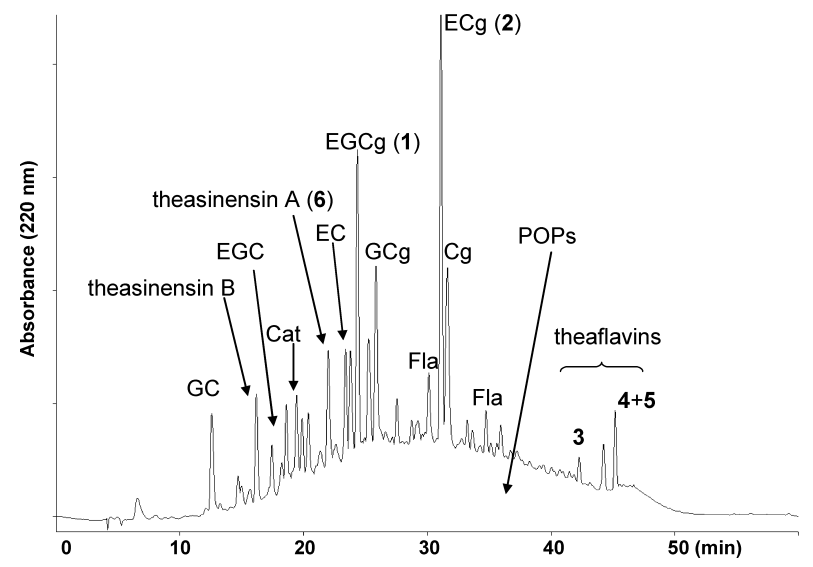

Fig. 1. HPLC Analysis of Polyphenol Fraction Obtained from Commercial Bottled Black Tea

Isomers of tea catechins produced during heat sterilization were observed. GC: gallocatechin, EGC: (-)-epigallocatechin, Cat: catechin, EC: $(-)$-epicatechin, ECg: $(-)$ epicatechin 3-O-gallate, EGCg: (-)-epigallocatechin 3-O-gallate, $\mathrm{GCg}$ : (-)-gallocatechin 3-O-gallate, $\mathrm{Cg}$ : (-)-catechin 3-O-gallate, Fla: flavonol glycosides. 
Table 1. Lipase Inhibition Activities of Fractions and Polyphenols ${ }^{a)}$

\begin{tabular}{lc}
\hline \hline & Inhibition (\%) \\
\hline AcOEt L. & $47.7 \pm 2.6$ \\
BuOH L. & $46.8 \pm 5.4$ \\
Aqeous L. & $28.3 \pm 8.5$ \\
Insoluble precipitates & $61.1 \pm 9.8$ \\
Epigallocatechin 3-O-gallate (1) & $14.5 \pm 13.2$ \\
Theaflavin (3) & $0.0 \pm 0$ \\
Theaflavin 3-O-gallate (4) & $29.6 \pm 7.5$ \\
Theaflavin 3,3'-di- $O$-gallate (5) & $48.9 \pm 2.8$ \\
Procyanidin-B-4 (8) & $31.8 \pm 1.6$ \\
Procyanidin-B-3 (9) & $13.4 \pm 4.7$ \\
Theasinensin A (6) & $24.6 \pm 1.6$ \\
Galloyl oolongtheanin (7) & $55.9 \pm 13.6$ \\
BLS1 (caffeine and small amount of POP) & $5.3 \pm 9.1$ \\
BLS2 (POP+theaflavin gallates) & $33.8 \pm 16.4$ \\
BLS3 (POP) & $65.3 \pm 9.7$ \\
BLP1 (caffeine and small amount of POP) & $14.6 \pm 20.3$ \\
BLP2 (POP+theaflavin gallates) & $65.2 \pm 8.8$ \\
BLP3 (POP) & $80.3 \pm 4.4$ \\
\end{tabular}

a) $0.04 \mathrm{mg} / \mathrm{ml}$.

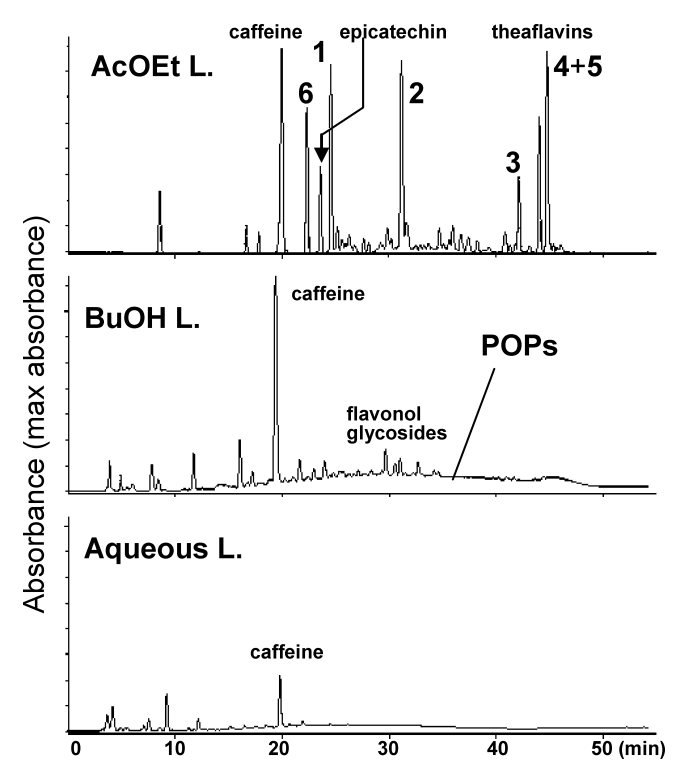

Fig. 2. HPLC Analysis of the Fractions of Black Tea Obtained from an Aqueous Acetone Extract
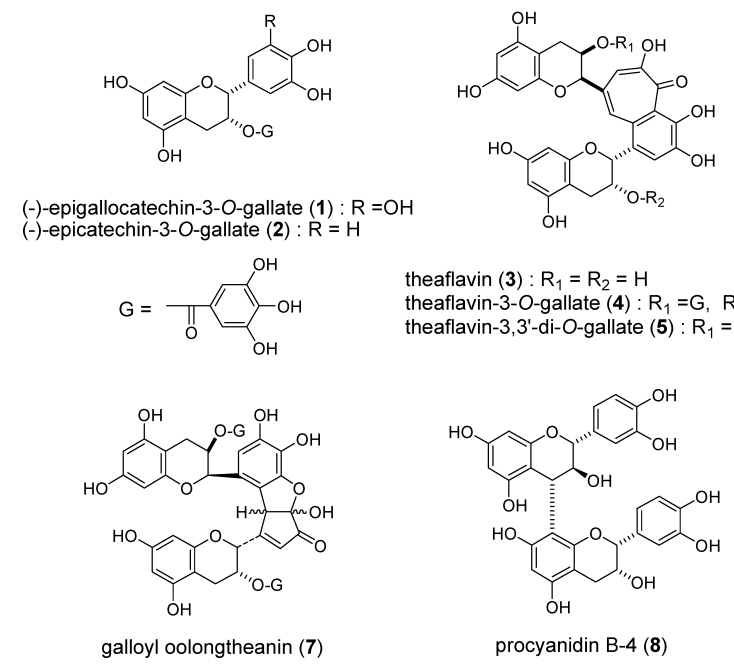

theaflavin $(3): R_{1}=R_{2}=H$
theaflavin-3-O-gallate $(4): R_{1}=G, R_{2}=H$
theaflavin-3,3'-di-O-gallate $(5): R_{1}=R_{2}=G$

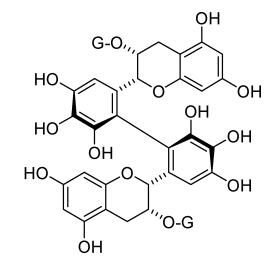

theasinensin A (6)

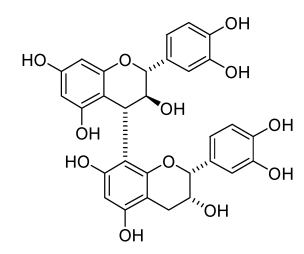

procyanidin B-4 (8)

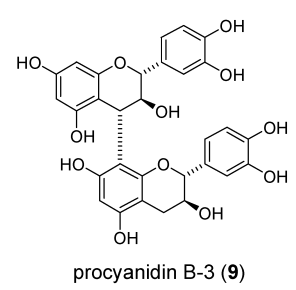

Fig. 3. Structure of Catechin Oxidation Products and Procyanidins

some structure-defined polyphenols are listed in Table 1, and the activity of the EtOAc layer was probably attributable to these catechin oxidation products. Galloyl oolongtheanin (7) showed a stronger inhibition than the theaflavin digallate (5), and this was in agreement with the results of Nakai et al. ${ }^{18)}$ In contrast, the HPLC analysis of the $n-\mathrm{BuOH}$ layer showed the presence of uncharacterized polyphenols that were detected as a broad hump on the HPLC baseline (polymer-like oxidation products; POPs) (Fig. 2). In a TLC analysis, the POPs were detected at the origin and positive to the $\mathrm{FeCl}_{3}$ reagent (dark greenish-blue) and vanillin- $\mathrm{HCl}$ reagent (red) characteristic to catechin related compounds. The activity of the $\mathrm{BuOH}$ layer was comparable to that of the EtOAc layer, and the yield (10.6\% of black tea dry weight) was much higher than that of the EtOAc layer (4.7\%); thus, the $\mathrm{BuOH}$ soluble fraction was important in the total inhibition activity of black tea. Although the yield $(0.5 \%)$ was very low, the insoluble precipitate showed the strongest activity $(61.1 \%)$ of the fractions. HPLC analysis of the precipitate indicated that it was mainly composed of POPs, and the HPLC profile was similar to that of the $n-\mathrm{BuOH}$ fraction. A large part of the POPs in the $n-\mathrm{BuOH}$ layer was precipitated from aqueous methanol to produce a brown powder designated as BLPs (precipitates obtained from $n$-BuOH layer), and the supernatant (BLS) also contained POPs. The BLPs were separated by Sephadex LH-20 column chromatography into three parts that contained mainly caffeine (BLP-1), POPs with a small amount of theaflavin gallates (BLP-2), and pure POPs (BLP3), respectively. Similarly, BLS was also separated into three fractions (BLS-1, 2, 3). The lipase inhibitory activities of these fractions are listed in Table 1, and BLP-3 showed the strongest inhibition. HPLC analysis revealed that the peak summit retention times of BLP-3 and BLS-3 differed (Fig. 4A), and BLP-3 was retained in the HPLC column more strongly. Direct size-exclusion chromatography of these fractions using an acetone-containing acidic aqueous urea solution as the elution solvent ${ }^{19)}$ suggested that the molecular size of BLP-3 was larger than that of BLS-3, indicating that POPs with larger molecular weights showed stronger inhibitory activities (Fig. 4B). The POPs also showed strong $\alpha$-amylase 
inhibitory activity (Table 2). The result suggested that the POPs of black tea also affect starch digestion, because the concentration of POPs in the black tea infusion was higher than that of theaflavin-3,3'-di-O-gallate (5), a black tea pigment used as a positive control (Fig. 1). ${ }^{16)}$

Chemical Study on the Polymer-Like Oxidation Products Since production of POPs during tea fermentation was accompanied by a decrease in concentrations of catechins, it was deduced that POPs were oxidation products of catechins. The ${ }^{1} \mathrm{H}-\mathrm{NMR}$ spectrum of BLP-3 showed broad peaks at $\delta$ $7.0,6.0$ and 2.8 that were attributable to galloyl $\mathrm{H}-2,6$, catechin A-ring H-6, 8 and C-ring H-4, respectively (Fig. 5). The inverse-gated decoupling ${ }^{13} \mathrm{C}$-NMR spectrum also showed broad signals attributable to the galloyl group $[\delta 121(\mathrm{C}-1)$, 109 (C-2, 6), 145 (C-3, 5), 138 (C-4), 165 (C-7)] catechin Aring $[\delta 95(\mathrm{C}-6,8), 100(\mathrm{C}-4 \mathrm{a}), 155-157(\mathrm{C}-5,7,8 \mathrm{a})]$, indicating that POPs are a mixture of oxidation products of tea catechins.

The enzymatic oxidation of a mixture of four pure tea catechins, and subsequent purification followed by size-exclusion chromatography resulted in POPs which showed almost

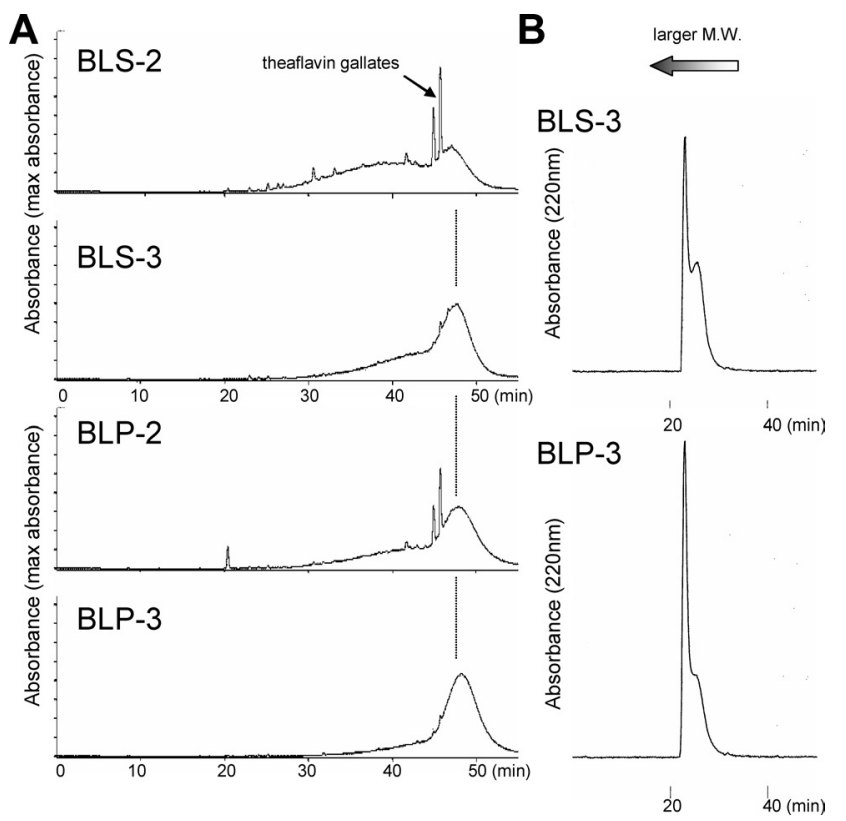

Fig. 4. Reversed-Phase and Size-Exclusion HPLC of POPs

(A) Reversed-phase HPLC. (B) Size-exclusion HPLC. the same resonance peaks in the ${ }^{1} \mathrm{H}$ - and ${ }^{13} \mathrm{C}$-NMR spectra. The results supported the proposal that POPs obtained from black tea were oxidation products of tea catechins. In addition, the absence of catechol- and pyrogallol-type B-ring signals in the NMR spectra suggested that the POPs were produced by oxidative condensation of $\mathrm{B}$ rings, which was probably related to the formation of theasinensins (6) and theaflavins (3-5) (Fig. 3). Gel Permeation Chromatography (GPC) of BLP-3 using TSK-gel $\alpha-3000$ suggested that the peak top molecular weight was $9700{ }^{20)}$ Measurement of the total polyphenol content in BLP-3 by the Folin-Ciocalteau method $^{21)}$ using 1 as the standard showed that the polyphenol content of BLP-3 was only $50 \%$. This suggested that phenolic benzene rings may be oxidatively degraded to non-phenolic forms, such as carboxylic acid. ${ }^{22)}$ HPLC analysis of the thiol degradation products using 2-mercaptoethanol as a nucleophile ${ }^{23)}$ showed the production of trace amounts of epicatechin, epicatechin 3-O-gallate, catechin-4-hydroxyethylthioether, and epicatechin-4-hydroxyethylthioether. This indicated the presence of procyanidin-like C-4 $-\mathrm{C}-8(6)$ interflavan linkages; however, the apparent decrease in size of the broad hump on the base-line was not observed in this degradation reaction. Therefore, the procyanidin-type linkage does not appear to be an important component of POPs. Ethanolysis in ethanolic hydrogen chloride yielded gallic acid ethyl ester as the major product. The amounts of the galloyl group in BLP-3 and BLS-3 were $5.5 \pm 0.1 \%$ and $7.0 \pm 0.1 \%$, respectively. Since the percentage of the galloyl group in $\mathbf{1}$ is $33 \%$, the proportion of the galloyl group in POPs was not high. The lipase inhibitory activity of BLP-3 was higher than BLS3 , where the molecular size of the former is larger than that

Table 2. $\alpha$-Amylase Inhibition Activities of Fractions and Polyphenols ${ }^{a}$ )

\begin{tabular}{lc}
\hline \hline & Inhibition (\%) \\
\hline AcOEt L. & $65.4 \pm 4.1$ \\
BuOH L. & $57.0 \pm 1.8$ \\
Aqeous L. & $5.3 \pm 1.1$ \\
BLS1 (caffeine and small amount of POP) & $10.4 \pm 1.1$ \\
BLS2 (POP + theaflavin gallates) & $64.8 \pm 3.2$ \\
BLS3 (POP) & $62.3 \pm 2.9$ \\
BLP1 (caffeine and small amount of POP) & $36.8 \pm 0.2$ \\
BLP2 (POP+theaflavin gallates) & $60.4 \pm 5.1$ \\
BLP3 (POP) & $53.7 \pm 3.3$ \\
Theaflavin 3,3' ${ }^{\prime}$-di- $O$-gallate $(5)^{b)}$ & $81.6 \pm 2.8$
\end{tabular}

a) $0.04 \mathrm{mg} / \mathrm{ml}$. b) Positive control.

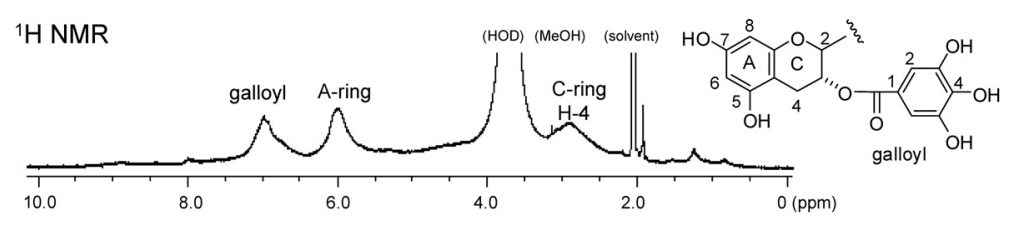

${ }^{13} \mathrm{C}$ NMR

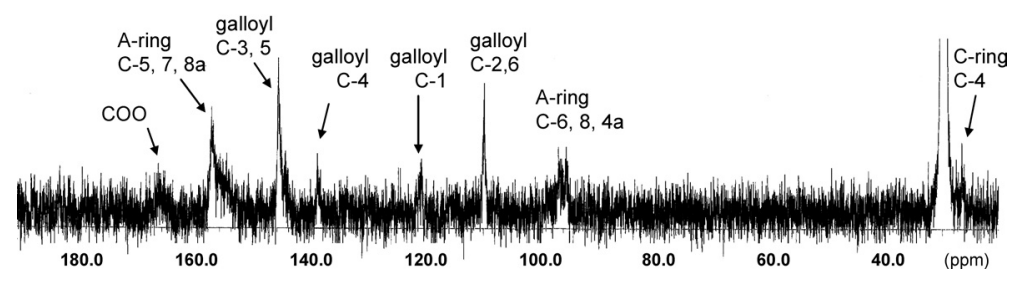

Fig. 5. ${ }^{1} \mathrm{H}-$ and ${ }^{13} \mathrm{C}-\mathrm{NMR}$ Spectra of BLP-3 
of the latter, as mentioned previously (Fig. 4). Therefore, the results indicated that the molecular size of POPs is more important for enzyme inhibitory activity than the amounts of galloyl esters. Furthermore, the lower content of galloyl groups in BLP-3 suggested that galloyl groups were oxidized when the molecule was extended.

Previous studies suggested that intermolecular oxidative couplings of catechins mainly occur between two B-rings, and generally give dimeric products such as 3-7. Further extension of the molecule at the B-rings of the products were not observed, ${ }^{1,4,5,22)}$ except for the oxidative coupling at the benzotropolone moieties of theaflavin, which yielded bistheaflavins A and $\mathrm{B}^{24)}$ However, when epicatechin 3-Ogallate (2) was enzymatically oxidized with the polyphenoloxidase of the Japanese pear homogenate, ${ }^{22,24)}$ a polymeric substance similar to POPs was produced. The HPLC and ${ }^{13} \mathrm{C}$-NMR spectra of the polymeric substance derived from 2 (Fig. 6) were related to those of BLP-3, and the peaktop molecular weight was estimated to be 8100 by GPC. The ${ }^{13} \mathrm{C}$-NMR spectrum of the polymeric substance showed signals attributable to the galloyl groups, as well as those due to the A- and C-rings; the galloyl C-2, 6 signals were smaller than the A-ring signals. This observation suggested that significant amounts of the galloyl groups were oxidized during production of the polymeric substance. The major product of the reaction was theaflavate A (10) ${ }^{25)}$ which is a dimer produced by intermolecular oxidative condensation between the catechol B-ring and the galloyl group (Chart 1). In addition, theaflavate $\mathrm{C}$ (11), an extended trimer of $\mathbf{2}$, was isolated from the same reaction mixture. Furthermore, bistheaflavate A (12), a tetramer of $\mathbf{2}$ produced by oxidative coupling between two benzotropolone moieties of $\mathbf{1 0}$ were also produced. ${ }^{26)}$ Since intermolecular coupling between the B-ring and galloyl group extends the molecular size as shown in $\mathbf{1 0}$ and $\mathbf{1 1}$,

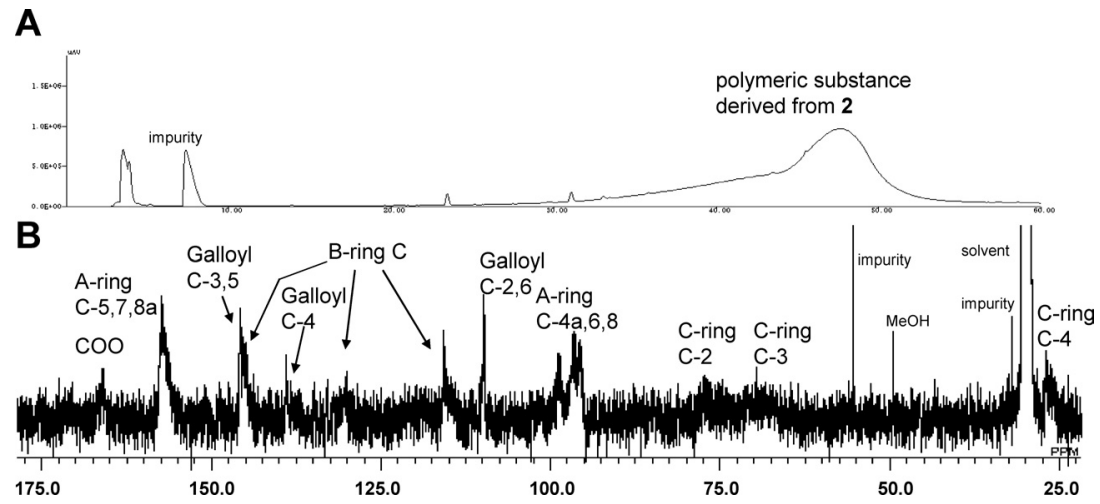

Fig. 6. HPLC (A) and ${ }^{13} \mathrm{C}-\mathrm{NMR}$ (B) Spectra of a POP-Like Substance Produced from Epicatechin 3-O-Gallate

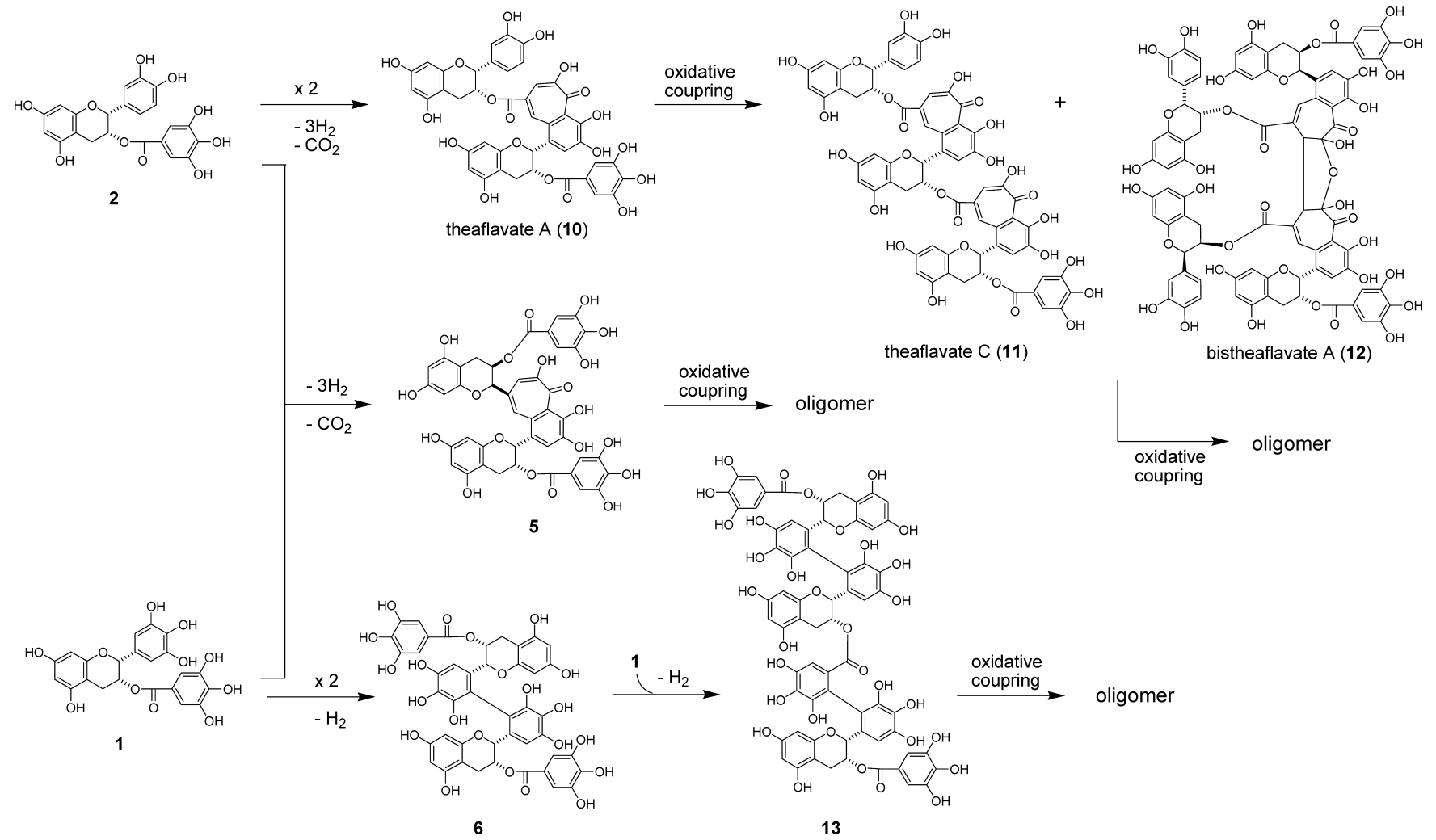

Chart 1. Possible Mechanism for Production of POPs 
the polymeric substance may be produced by a related polymerization reaction. This was supported by the MALDITOF-MS analysis of a fraction containing the oxidation products of 2 with lower molecular weights obtained from the same reaction mixture, which exhibited peaks corresponding to the tetramer and pentamer $\left[\mathrm{m} / \mathrm{z}: 875\left(\mathbf{1 0},[\mathrm{M}+\mathrm{Na}]^{+}\right), 1285\right.$ (corresponding to a trimer 11, $[\mathrm{M}+\mathrm{Na}]^{+}$), 1740 (tetramer) and 2175 (pentamer)]. Similar oxidative couplings of galloyl groups attached to theasinensins and theaflavins occur during tea fermentation. In particular, the production of trimer $\mathbf{1 3}$ from 1 by enzymatic oxidation was previously demonstrated (Chart 1). ${ }^{27,28)}$ Moreover, the extension of the molecule may also occur at the benzotropolone ring in a manner similar to the formation of $\mathbf{1 2}$ and bistheaflavins $\mathrm{A}$ and $\mathrm{B} .{ }^{24)}$

\section{Conclusion}

Black tea contains a variety of polyphenols including tea catechins and chemically uncharacterized oxidation products, where the complexity of black tea polyphenols has hampered the evaluation of their biological functions. The complexity is caused by cascade-type complex oxidation between four tea catechins during black tea production. ${ }^{22,28,29)}$ The importance of some characteristic polyphenols, such as theaflavins, is already known; however, the present study has shown the importance of POPs (obtained by extraction in $n$-BuOH) as the active components inhibiting pancreatic lipase and $\alpha$ amylase. BLP-3 represented the fraction of POPs with the strongest enzyme inhibitory activities. Although this fraction was not soluble in water when purified, it remained in the water layer of the black tea extract on partitioning with EtOAc. It is likely that these POPs were solubilized by interaction with coexisting water-soluble substances such as flavonol glycosides, as observed for polymeric proantocyanidins. ${ }^{14,30)}$ POPs are a mixture of catechin oxidation products that could not be detected as sharp peaks by HPLC analysis. These POPs may be partly identical with thearubigins, which are uncharacterized black tea polyphenols as designated by Roberts, ${ }^{6,31)}$ and are widely considered to account for a major part of polyphenols in black tea infusions. ${ }^{6}$ ) The results of the in vitro oxidation of $\mathbf{2}$ suggested that oxidative coupling of galloyl groups with other B-rings was important for the production of POPs such as BLP-3, in addition to B-B-ring couplings (Chart 1). Further studies concerning the structure and mechanism of the production of POPs are now in progress.

\section{Experimental}

General Experimental Procedures UV spectra were obtained with a JASCO V-560 UV/VIS spectrophotometer. ${ }^{1} \mathrm{H}$ - and ${ }^{13} \mathrm{C}$-NMR spectra were recorded in a mixture of acetone- $d_{6}$ and $\mathrm{D}_{2} \mathrm{O}(19: 1, \mathrm{v} / \mathrm{v})$ at $27^{\circ} \mathrm{C}$ with a Varian Unity Plus 500 spectrometer operating at $500 \mathrm{MHz}$ for ${ }^{1} \mathrm{H}$ and $125 \mathrm{MHz}$ for ${ }^{13} \mathrm{C}$. Mass spectra (MS) were recorded on a Voyager-DE Pro spectrometer, and 2,5-dihydroxybenzoic acid $(10 \mathrm{mg} / \mathrm{ml}$ in $50 \%$ acetone containing $0.05 \%$ trifluoroacetic acid) was used as the matrix for MADLITOF-MS measurements. Column chromatography was performed using Sephadex LH-20 (25-100 $\mu$ m, Pharmacia Fine Chemical Co. Ltd.). Thin layer chromatography was performed on precoated Kieselgel $60 \mathrm{~F}_{254}$ plates (0.2-mm thick, Merck) with benzene-ethyl formate-formic acid $(1: 7: 1$, $\mathrm{v} / \mathrm{v}), \mathrm{CHCl}_{3}-\mathrm{MeOH}$-water $(14: 6: 1, \mathrm{v} / \mathrm{v})$ and Cellulose $\mathrm{F}_{254}$ (0.2-mm thick, Merck) with $2 \% \mathrm{AcOH}$. Spots were detected using ultraviolet (UV) illumination and by spraying with $2 \%$ ethanolic $\mathrm{FeCl}_{3}$ or $10 \%$ sulfuric acid reagent followed by heating. Analytical HPLC was performed on a Cosmosil $5 \mathrm{C}_{18}$ AR II (Nacalai Tesque, Inc.) column $(250 \times 4.6 \mathrm{~mm}$ i.d.) with gradient elution from $4-30 \%(39 \mathrm{~min})$ and $30-75 \%(15 \mathrm{~min})$ of $\mathrm{CH}_{3} \mathrm{CN}$ in $50 \mathrm{~mm}$ $\mathrm{H}_{3} \mathrm{PO}_{4}$ (flow rate, $0.8 \mathrm{ml} / \mathrm{min}$; detection, JASCO photodiode array detector MD-910).
Materials Glyceryl trioleate, pancreatic lipase (type II) and butylated hydroxyanisole were purchased from Sigma (St. Louis, U.S.A.). Lecithin (from egg), bathocuproine, sodium cholate, 3,5-dinitrosalycilic acid (DNS), and $\mathrm{Cu}\left(\mathrm{NO}_{3}\right)_{2} \cdot 3 \mathrm{H}_{2} \mathrm{O}$ were purchased from Wako Pure Chemical Industries, Ltd. (Osaka, Japan). $N$-Tris(hydroxymethyl)methyl-2-aminoethane sulfonic acid (TES) was purchased from Kishida Chemical Co., Ltd. (Osaka, Japan). Epicatechin 3-O-gallate, epigallocatechin and epigallocatechin 3-O-gallate were isolated from green tea ${ }^{4}{ }^{4}$ Theaflavin, theaflavin 3-O-gallate, theaflavin$3,3^{\prime}$-di- $O$-gallate, ${ }^{32)}$ oolongtheanin gallate, ${ }^{5,22)}$ and theasinensins $\mathrm{A}^{22,33)}$ were obtained by enzymatic oxidation of tea catechins in our previous research.

HPLC Analysis of Commercial Black Tea Bottled commercial black tea (heat sterilized) (3.01) was directly applied to Sephadex LH-20 (25X $3.0 \mathrm{~cm}$ i.d.) and washed with $25 \% \mathrm{MeOH}$ to remove sugars and caffeine. The polyphenols adsorbed on the gel was eluted out with $\mathrm{MeOH}(200 \mathrm{ml})$ and then $50 \%$ aqueous acetone $(400 \mathrm{ml})$. After removal of the organic solvents by rotary evaporator, the aqueous solution of the polyphenols was lyophilized to give brown powder $(1.69 \mathrm{~g})$, which was analyzed by reversed phase HPLC (Fig. 1)

Measurement of Amylase Inhibitory Activity Amylase inhibition was measured according to a published method. ${ }^{16,34)}$ Briefly, a sample in $0.1 \mathrm{ml}$ of $20 \mathrm{~mm}$ phosphate buffer ( $\mathrm{pH}$ 6.9) containing $6.7 \mathrm{~mm} \mathrm{NaCl}$ was mixed with $0.5 \mathrm{ml}$ of amylase solution $(0.03 \mathrm{mg} / \mathrm{ml}$ in the above buffer) and incubated at $37^{\circ} \mathrm{C}$ for $10 \mathrm{~min}$. To the mixture, $0.4 \mathrm{ml}$ of a starch solution $(3 \mathrm{mg} / \mathrm{ml}$ in the above buffer) was added and incubated further for $1 \mathrm{~h}$. A portion $(0.4 \mathrm{ml})$ of the reaction mixture was taken and mixed with $0.4 \mathrm{ml}$ of DNS reagent ${ }^{34)}$ and heated at $100^{\circ} \mathrm{C}$ for $5 \mathrm{~min}$ in a screw-capped vial. After cooling on ice, the solution was diluted with the addition of $4 \mathrm{ml}$ of water and the absorption at $540 \mathrm{~nm}$ was measured. Theaflavin $3,3^{\prime}$-di- $O$-gallate was used as the positive control. $^{16)}$

Measurement of Lipase Inhibitory Activity The investigation of lipase inhibitory activity was based on the method of Han et al. ${ }^{35}$ using glyceryl trioleate as the substrate. The substrate solution was prepared by sonication of a mixture of glyceryl trioleate $(80 \mathrm{mg})$, lecithin $(10 \mathrm{mg})$ and sodium cholate $(5 \mathrm{mg})$ in $9 \mathrm{ml}$ of $0.1 \mathrm{~m}$ TES buffer $(\mathrm{pH} 7)$. The substrate solution $(0.1 \mathrm{ml})$ was mixed with a sample solution $(0.1 \mathrm{ml})$ and preincubated at $37^{\circ} \mathrm{C}$ for $5 \mathrm{~min}$. After addition of $0.05 \mathrm{ml}$ of a lipase solution $(0.05 \mathrm{mg} / \mathrm{ml})$ the mixture was further incubated for $30 \mathrm{~min}$. Free fatty acids generated by this procedure were measured according to the method of Tsujita and Zapf. ${ }^{36,37)}$ The reaction mixture $(125 \mu \mathrm{l})$ was added to $3 \mathrm{ml}$ of $\mathrm{CHCl}_{3}$-heptane $(1: 1, \mathrm{v} / \mathrm{v})$ containing $2 \%(\mathrm{v} / \mathrm{v}) \mathrm{MeOH}$ and shaken horizontally for $10 \mathrm{~min}$. The mixture was centrifuged at $2000 \mathrm{~g}$ for $10 \mathrm{~min}$ and $1 \mathrm{ml}$ of the lower organic phase was taken and mixed with $1 \mathrm{ml}$ of copper reagent. ${ }^{37)}$ The test tube was shaken vigorously for $10 \mathrm{~min}$ and centrifuged at $2000 \boldsymbol{g}$ for $10 \mathrm{~min}$. The upper organic phase $(0.5 \mathrm{ml})$ containing fatty acid copper salts was reacted with $0.5 \mathrm{ml}$ of $0.1 \%(\mathrm{w} / \mathrm{v})$ bathocuproine in $\mathrm{CHCl}_{3}$ containing $0.05 \%(\mathrm{w} / \mathrm{v})$ butylated hydroxyanisole to produce a pale orange-colored complex, and absorption of the solution at $480 \mathrm{~nm}$ was measured. Preparation of the copper reagent was as follows: $\mathrm{Cu}\left(\mathrm{NO}_{3}\right)_{2}(1.21 \mathrm{~g})$ was dissolved in a $1 \mathrm{M}$ triethanolamine solution $(10 \mathrm{ml})$ and mixed with a $1 \mathrm{~m} \mathrm{NaOH}$ solution $(6 \mathrm{ml}) . \mathrm{NaCl}(33 \mathrm{~g})$ was added to the solution and the total volume was then adjusted to $100 \mathrm{ml}$ with water.

Extraction and Isolation for Comparison of Lipase Inhibitory Activity Commercial black tea (919g, tea bag produced in India) was extracted with water, three times at room temperature. The extract was applied directly to a Sephadex LH-20 column $(10 \times 31 \mathrm{~cm})$ and washed with $\mathrm{H}_{2} \mathrm{O}$ to remove sugars and caffeine. The adsorbed polyphenols were fractionated into fractions $1-10$ by a $20 \%$ stepwise gradient elution with water- $\mathrm{MeOH}(0$ $100 \%)$ and then $\mathrm{MeOH}-\mathrm{H}_{2} \mathrm{O}$-acetone $(8: 1: 1 \rightarrow 3: 1: 1)$. The residue remaining after extraction with water was further extracted with $50 \%$ aqueous acetone three times and the acetone was evaporated in vacuo. The resulting aqueous solution $(21)$ was successively partitioned with ether $(11 \times 3)$, EtOAc $(11 \times 4)$, and $n-\mathrm{BuOH}(11 \times 4)$ to produce an ether soluble fraction (29.4 g, 3.2\% of black tea dry weight), an EtOAc fraction (43.6 g, 4.7\%), an $n$-BuOH fraction $(97.0 \mathrm{~g}, 10.6 \%)$, and a water fraction $(82.4 \mathrm{~g}, 9.0 \%)$. The paste-like precipitate $(4.3 \mathrm{~g}, 0.5 \%)$ remaining in the final aqueous layer was collected. The lipase inhibitory activity of the ten fractions obtained from the initial water extract, and that of the ether and $\mathrm{CHCl}_{3}$ fractions, was weak (less than 30\% inhibition) and these fractions were not examined further.

Separation of the $\boldsymbol{n}$-BuOH Layer The $n$-BuOH fraction $(65 \mathrm{~g})$ was dissolved in $50 \% \mathrm{MeOH}(500 \mathrm{ml})$ by heating and left to stand at room temperature for $10 \mathrm{~h}$. The resulting brown precipitate was collected by centrifugation. The addition of $\mathrm{H}_{2} \mathrm{O}$ to the supernatant $(\rightarrow$ about $30 \% \mathrm{MeOH})$ produced a further precipitate. The precipitates were combined to form an $n$-BuOH layer precipitate (BLP) fraction $(41.7 \mathrm{~g})$. The final supernatant was 
concentrated to produce an $n-\mathrm{BuOH}$ layer supernatant (BLS) fraction $(18.7 \mathrm{~g})$. These fractions were fractionated separately into three fractions using Sephadex LH-20 column chromatography $(50-100 \% \mathrm{MeOH}$ and then $50 \%$ aqueous acetone) to produce fractions BLP-1 (13.5 g, yield: $32.5 \%)$, BLP-2 (10.5 g, 25.3\%) and BLP-3 (7.7 g, 18.4\%) from BLP, and BLS-1 (9.6 g, 51\%), BLS-2 (7.8 g, 41.6\%) and BLS-3 (1.4 g, 7.4\%) from BLS. HPLC analysis demonstrated that BLP-1 and BLS- 1 contained caffeine and small amounts of polymer-like oxidation products (POPs), BLP-2 and BLS-2 contained POPs and small amounts of mono- and di-galloyl esters of theaflavin, and BLP-3 and BLS-3 contained only POPs. BLP-3 was obtained as a dark-brown amorphous powder with the following elemental constituents: C, $58.38 \%$; H, 4.44\%; N, 0.30\%.

Size-Exclusion HPLC of BLP-3 and BLS-3 Size-exclusion HPLC of BLP-3 and BLS-3 (Fig. 4B) was performed according to Yanagida et al. ${ }^{19)}$ using a TSK gel $\alpha-2500$ column $(300 \times 7.8 \mathrm{~mm}$ i.d.). The mobile phase was acetone- $6 \mathrm{~m}$ urea $(\mathrm{pH} 2)(3: 2)$, the flow rate was $0.1 \mathrm{ml} / \mathrm{min}$, and the eluate was monitored at $220 \mathrm{~nm}$.

Thiolysis of Polymer-Like Substance A solution of $0.1 \%(\mathrm{w} / \mathrm{v})$ POPs in $70 \% \mathrm{EtOH}(0.2 \mathrm{ml})$ was mixed with $5 \%$ mercaptoethanol in $60 \% \mathrm{EtOH}$ containing $0.1 \% \mathrm{HCl}(0.8 \mathrm{ml})$ and heated at $70{ }^{\circ} \mathrm{C}$ for $7 \mathrm{~h}$. HPLC analysis showed four small peaks. The retention time and UV absorption of the peaks coincided with those of epicatechin, catechin-4-hydroxyethylthioether, epicatechin 4-hydroxyethylthioether and epicatechin-3-O-gallate, and represents the order of their elution. ${ }^{23}$ However, the broad hump on the base-line did not decrease.

GPC Analysis of POPs POPs were dissolved in dimethylformamide and applied to a TSK-gel $\alpha 3000$ column $\left(300 \times 7.8 \mathrm{~mm}\right.$ i.d.) at $40{ }^{\circ} \mathrm{C}$ with dimethylformamide containing $10 \mathrm{~mm} \mathrm{LiCl}$ as the elution solvent at a flow rate of $0.5 \mathrm{ml} / \mathrm{min}$. The peaks were detected by monitoring UV absorption at $254 \mathrm{~nm}$. Polystyrene standards (molecular weights of 4000, 25000, 50000 and 170000), toluene (molecular weight 92), and three ellagitannins [1-O galloylpedunculagin (MW 936), ${ }^{38,39)}$ sanguiin H-6 (MW 1870), ${ }^{40)}$ and rubusuaviin C (MW 2804) ${ }^{39)}$ ] were used as standards. Peak-top molecular weights were recorded by an Integrator 807-IT (JASCO Corporation).

Ethanolysis of BLP-3 and BLS-3 BLP-3 and BLS-3 were dissolved separately in $1 \mathrm{M} \mathrm{HCl}$ in EtOH $(2 \mathrm{mg} / \mathrm{ml})$ and heated at $100^{\circ} \mathrm{C}$. The concentration of ethyl gallate in the reaction mixture was analyzed by HPLC at 12 , $24,36,48$ and $60 \mathrm{~h}$. The peak area did not increase after $48 \mathrm{~h}$. The yields of ethyl gallate from BLP-3 and BLS-3 were $7.1 \pm 0.1 \%(5.5 \pm 0.1 \%$ as galloyl group) and $9.1 \pm 0.1 \%(7.0 \pm 0.1 \%)$, respectively. The calibration curve was constructed using ethyl gallate prepared by a similar ethanolysis of tannic acid. Preparation of the standard ethyl gallate was as follows: tannic acid was heated in $1 \mathrm{~m} \mathrm{HCl}$ in EtOH under reflux for $12 \mathrm{~h}$. After solvent partitioning between EtOAc and water, the EtOAc layer was applied to a Sephadex LH-20 column with EtOH and further purified using silica gel $60\left(\mathrm{CHCl}_{3}-\right.$ $\left.\mathrm{MeOH}-\mathrm{H}_{2} \mathrm{O}, 90: 10: 1, \mathrm{v} / \mathrm{v} / \mathrm{v}\right)$ chromatography and crystallized from $\mathrm{CHCl}_{3}-$ $\mathrm{MeOH}$

Production of POPs Using a Model Fermentation Experiment Japanese pear fruit $(600 \mathrm{~g})$ was homogenized with water $(100 \mathrm{ml})$ in a mechanical blender and filtered through four layers of gauze. The homogenate $(300 \mathrm{ml})$ was mixed with an aqueous solution $(200 \mathrm{ml})$ containing $(-)$-epicatechin $(0.5 \mathrm{~g}),(-)$-epigallocatechin $(1.0 \mathrm{~g}),(-)$-epicatechin-3-O-gallate $(0.5$ $\mathrm{g})$ and $(-)$-epigallocatechin-3-O-gallate $(2.5 \mathrm{~g})$ and stirred vigorously for $3 \mathrm{~h}$. The mixture was heated at $90^{\circ} \mathrm{C}$ for $2 \mathrm{~min}$ to inactivate enzymes and decompose unstable quinone intermediates. ${ }^{22,41)}$ After cooling, the mixture was poured into acetone ( 21$)$ and filtered through No. 2 filter paper. The filtrate was concentrated until the organic solvent was removed, and the resulting aqueous solution $(400 \mathrm{ml})$ was successively partitioned with EtOAc $(400 \mathrm{ml} \times 4)$ and $n$-BuOH $(300 \mathrm{ml} \times 4)$. The $n$-BuOH layer was concentrated in vacuo and the residue was fractionated by size-exclusion chromatography using Sephadex LH-20 $(26 \times 1.5 \mathrm{~cm}$ i.d. $)$ with acetone: $6 \mathrm{~m}$ urea $(3: 2, \mathrm{v} / \mathrm{v}$, adjusted to $\mathrm{pH} 2$ with diluted $\mathrm{HCl}){ }^{19)}$ The POPs with larger molecular weights were eluted faster than catechins and theaflavins, and the fractions containing only POPs were combined. After evaporation of acetone, the aqueous solution was passed through Sephadex LH-20 $(12 \times 1.5 \mathrm{~cm}$ i.d. $)$ and washed with water to remove urea and $\mathrm{HCl}$. The POPs adsorbed on the gel were eluted using $50 \%$ aqueous acetone to give POPs $(70 \mathrm{mg}$ ).

Enzymatic Oxidation of 2 Japanese pear $(150 \mathrm{~g})$ was homogenized in $\mathrm{H}_{2} \mathrm{O}(150 \mathrm{ml})$ and filtered through four layers of gauze. The homogenate $(300 \mathrm{ml})$ was mixed with an aqueous solution of $2(1.0 \mathrm{~g}$ in $200 \mathrm{ml})$ and vigorously stirred for $4 \mathrm{~h}$ at room temperature. The reaction was monitored by reversed-phase HPLC. The mixture was poured into acetone (21), gently stirred for $30 \mathrm{~min}$, and the insoluble material was then removed by filtration The filtrate was concentrated by evaporation until the acetone was com- pletely removed. The resulting aqueous solution was applied to a Sephadex LH-20 column $(26 \times 4.5 \mathrm{~cm}$ i.d. $)$ with $0-100 \% \mathrm{MeOH}(10 \%$ stepwise elution, each $300 \mathrm{ml})$ and $50 \%$ aqueous acetone to yield 7 fractions. Fr. $1(15.9$ $\mathrm{mg}$ ) and Fr. $4(172 \mathrm{mg})$ were identified as epicatechin and 2, respectively, using TLC and HPLC comparisons. MALDI-TOF-MS of Fr. 5 showed peaks at $m / z 875\left(\mathbf{1 0},[\mathrm{M}+\mathrm{Na}]^{+}\right), 1285\left(\right.$ corresponding to a trimer $\left.11,[\mathrm{M}+\mathrm{Na}]^{+}\right)$, and Fr. 7 exhibited the peaks at $m / z 1740$ (tetramer) and 2175 (pentamer). Fr $6(266 \mathrm{mg})$ contained polymeric substances and was further separated using a Sephadex LH-20 column $(20 \times 1.5 \mathrm{~cm}$ i.d.) with $8 \mathrm{~m}$ urea in $60 \%$ acetone (adjusted to $\mathrm{pH} 2$ by conc. $\mathrm{HCl}$ ). Tubes containing polymeric substance and 10 were collected separately and concentrated by evaporation until the acetone was removed. The resulting aqueous solutions were applied separately to a MCI-gel CHP $20 \mathrm{P}$ column $(20 \times 3.0 \mathrm{~cm}$ i.d.). After washing the column with water to remove urea, the polyphenols were eluted with $\mathrm{H}_{2} \mathrm{O}-\mathrm{MeOH}$ $(10 \%$ stepwise elution from 0 to $60 \%$, each $100 \mathrm{ml})$ to produce the polymeric substance $(45.1 \mathrm{mg})$ and $\mathbf{1 0}(28.5 \mathrm{mg})$.

Acknowledgements The authors are grateful to Mr. K. Inada and Mr. N. Yamaguchi for NMR and MS measurements. This work was supported by a Grant-in-Aid for Scientific Research No. 18510189 from the Japan Society for the Promotion of Science.

\section{References}

1) Hashimoto F., Nonaka, G., Nishioka, I., Chem. Pharm. Bull., 40, 1383-1389 (1992)

2) Wang D., Kurasawa E., Yamaguchi Y., Kubota K., Kobayashi A., J. Agric. Food Chem., 49, 1900-1903 (2001).

3) Takino Y., Imagawa H., Horikawa H., Tanaka A., Agric. Biol. Chem., 28, 64-71 (1964).

4) Nonaka G., Kawahara O., Nishioka I., Chem. Pharm. Bull., 31, 39063914 (1983).

5) Hashimoto F., Nonaka G., Nishioka I., Chem. Pharm. Bull., 36 1676-1684 (1988).

6) Haslam E., Phytochemistry, 64, 61-73 (2003).

7) Luczaj W., Skrzydlewska E., Preventive Medicine 40, 910-918 (2005).

8) Way T.-Z., Lee H.-H., Kao M.-C., Lin J.-K., Eur. J. Cancer, 40, 2165-2174 (2004).

9) Krishnan R., Maru G. B., J. Agric. Food Chem., 52, 4261-4269 (2004).

10) Maity S., Ukil A., Karmakar A., Datta N., Chaudhuri T., Vedasiromoni J. R., Ganguly D. K., Das P. K., Eur. J. Pharmacol., 470, 103-112 (2003).

11) Sang S., Lambert J. D., Tian S., Hong J., Hou Z., Ryu J.-H., Stark R. E., Rosen R. T., Huang M.-T., Yang C. S., Ho C.-T., Bioorg. Med. Chem., 12, 459-467 (2004).

12) Mulder T. P. J., van Platerink C. J., Wijnand Schuyl P. J., van Amelsvoort J. M. M., J. Chromatogr. B, 760, 271-279 (2001).

13) Haslam E., "Practical Polyphenolics, from Structure to Molecular Recognition and Physiological Action," Cambridge University Press, Cambridge, 1988, pp. 138-177.

14) Zhang Y.-J., Tanaka T., Betsumiya Y., Kusano R., Matsuo A., Ueda T., Kouno I., Chem. Pharm. Bull., 50, 258-262 (2002).

15) Inokuchi J., Okabe H., Yamaichi T., Nagamatsu A., Nonaka G., Nishioka I., Chem. Pharm. Bull., 33, 264-269 (1985).

16) Hara Y., Honda M., Agric. Biol. Chem., 54, 1939-1945 (1990).

17) Matsui T., Tanaka T., Tamura S., Toshima A., Tamaya K., Miyata Y., Tanaka K., Matsumoto K., J. Agric. Food Chem., 55, 99-105 (2007).

18) Nakai M., Fukui Y., Asami A., Toyoda-Ono Y., Iwashita T., Shibata H., Mitsunaga T., Hashimoto F., Kiso Y., J. Agric. Food Chem., 53, 4593-4598 (2005).

19) Yanagida A., Shoji T., Shibusawa Y., J. Biochem. Biophys. Methods, 56, 311-322 (2003).

20) Fujiwara T., Nakagawa-Izumi A., Osawa T., Numata O., Biosci. Biotechnol. Biochem., 71, 711-719 (2007).

21) Piccinelli A. L., Simone F., Passi S., Rastrelli L., J. Agric. Food Chem., 52, 5863-5868 (2004).

22) Tanaka T., Watarumi S., Matsuo Y., Kamei M., Kouno I., Tetrahedron, 59, 7939-7947 (2003)

23) Tanaka T., Takahashi R., Kouno I., Nonaka G., J. Chem. Soc. Perkin Trans. 1, 1944, 3013-3022 (1994).

24) Tanaka T., Inoue K., Betsumiya Y., Mine C., Kouno I., J. Agric. Food Chem., 49, 5785-5789 (2001).

25) Wan X., Nursten H. E., Cai Y., Davis A. L., Wilkins J. P. G., Davies A 
P., J. Sci. Food Agric., 74, 401-408 (1997).

26) Kusano R., Tanaka T., Matsuo Y., Kouno I., Chem. Pharm. Bull., 55, $1768-1772$ (2007).

27) Tanaka T., Matsuo Y., Kouno I., J. Agric. Food Chem., 53, 7571-7578 (2005).

28) Li Y., Tanaka T., Kouno I., Phytochemistry, 68, 1081-1088 (2007).

29) Tanaka T., Matsuo Y., Li Y., Kouno I., "Polyphenols Communications 2006," ed. by Daayf F., El Hadrami A., Adam L., Ballance G. M., University of Manitoba, Manitoba, 2006, pp. 115-116.

30) Tanaka T., Kataoka M., Tsuboi N., Kouno I., Chem. Pharm. Bull., 48, 201-207 (2000).

31) Roberts E. A. H., "The Chemistry of Flavonoid Compounds," ed. by Geissman T. A., Pergamon Press, Oxford, 1962, pp. 468-512.

32) Tanaka T., Mine C., Inoue K., Matsuda M., Kouno I., J. Agric. Food Chem., 50, 2142-2148 (2002).

33) Matsuo Y., Tanaka T., Kouno I., Tetrahedron, 62, 4774-4783 (2006).
34) Bernfeld P., "Methods in Enzymology," Vol. 1, ed. by Colowick S. P., Kaplan N. O., Elsevier, Amsterdam, 1955, pp. 149-158.

35) Han L.-K., Gong X.-J., Kawano S., Saito M., Kimura Y., Okuda H., Yakugaku Zasshi, 125, 213-217 (2005).

36) Tsujita T., Okuda H., Eur. J. Biochem., 133, 215-220 (1983).

37) Zapf J., Schoenle E., Waldvogel M., Sand I., Froesch E. R., Eur. J. Biochem., 113, 605-609 (1981).

38) Okuda T., Yoshida T., Ashida M., Yazaki K., J. Chem. Soc., Perkin. Trans 1, 1983, 1765-1772 (1983).

39) Li H., Tanaka T., Zhang Y.-J., Yang C.-R., Kouno I., Chem. Pharm. Bull., 55, 1325-1331 (2007).

40) Tanaka T., Nonaka G., Nishioka I., J. Chem. Res. (M), 1985, 20012029.

41) Tanaka T., Mine C., Watarumi S., Fujioka T., Mihashi K., Zhang Y.-J., Kouno I., J. Nat. Prod., 65, 1582-1587 (2002). 